\title{
Understanding the Development of Netflix during Recent Years through Data Visualization
}

\author{
Wanqi Zhang \\ School of Arts \& Sciences, University of Rochester, Rochester, NY 14627, USA
}

\begin{abstract}
In recent years, the development of video streaming media has influenced the way traditional industries are shaped. Amazon Prime Video, Netflix, Hulu, and Disney Plus are all magnates leading the industry. And Netflix, as a media that is loved by audiences throughout the globe, is known for its successful transformation and original contents. The objective of this article is to use the techniques of data visualization to tell the story of how Netflix developed in recent years, including its global layout, financial performance, content addition, and audience growth. By using Tableau to create different tables and charts, this article is able to show the trend of Netflix's development and invoke insights about its current operation, especially under the global pandemic.
\end{abstract}

Keywords: Netflix; Video Streaming Media; Data Visualization.

\section{Introduction}

In the $21^{\text {st }}$ century, as we break through the dimensions from text to pictures and then to videos, the need of video streaming grows rapidly. Netflix, being one of the biggest streaming media in the US and in the world, provides a great example of how this industry develops and is worth studying for.

According to Grand View Research, the global video streaming market size was estimated at USD 50.11 billion in 2020 and is expected to expand at a compound annual growth rate (CAGR) of $21.0 \%$ from 2021 to 2028. Leading the game, Netflix received 37 million paid memberships and USD 25 billion annual revenue at the end of 2020. Netflix is seeing continuous growth in its revenue and subscribers, partially due to the huge surge of demand increase in indoor personal entertainment brought by COVID-19. Netflix is expanding its movie and TV show library to keep up the demand and produce more high-quality shows for subscribers.

This dataset consists of variables including country, region, year, revenue, stock price, subscriber, amount of content, hours of original content, genre and so on. The data visualization will give users an overview of the development of Netflix in recent years from different aspects.

\section{Literature Review}

João and Ricardo (2021) utilizated a two-way fized effects estimator with state-month observations to show that the increase in Netflix popularity is associated with reduction of cable TV subscribers and number of small firms operating cable TV. Ramasoota and Abhibhu (2021) used several statistics and charts to show that Netflix has affected both the industry chains in broadcast and film, but with contrasting impacts. While broadcasters have gone online as content providers acquiring business deals with other OTTs, independent filmmakers could bypass the monopoly of Thai film industry through Netflix. Shon et al., (2021) examined the global OTT platforms, specifically Youtube and Netflix, in South Korea on efficiency differences in local video production and distribution industries by using stochastic frontier analysis and meta-frontier analysis. As they performed the analysis, they found that the platforms did have impacts on the domestic industry. Husić and Baraković (2021) stated that the Covid-19 pandemic has increased the use of video streaming service, and has driven a rising interest to understand factors influencing quality of experience (QoE). By providing the multidimensional modelling and analysis of QoE for video streaming, the authors showed that factors including location, video type, and gender had shown significant impacts on QoE. Bridge et al., (2019) used segmented quasi-Poisson regression and Holt-Winters forecasting models and found out that 
release of this Netflix original show is followed by a significant increase of suicide rate among 10 to 17-year-olds, which revealed the huge impact Netflix's shows had on the society.

\section{Discussion}

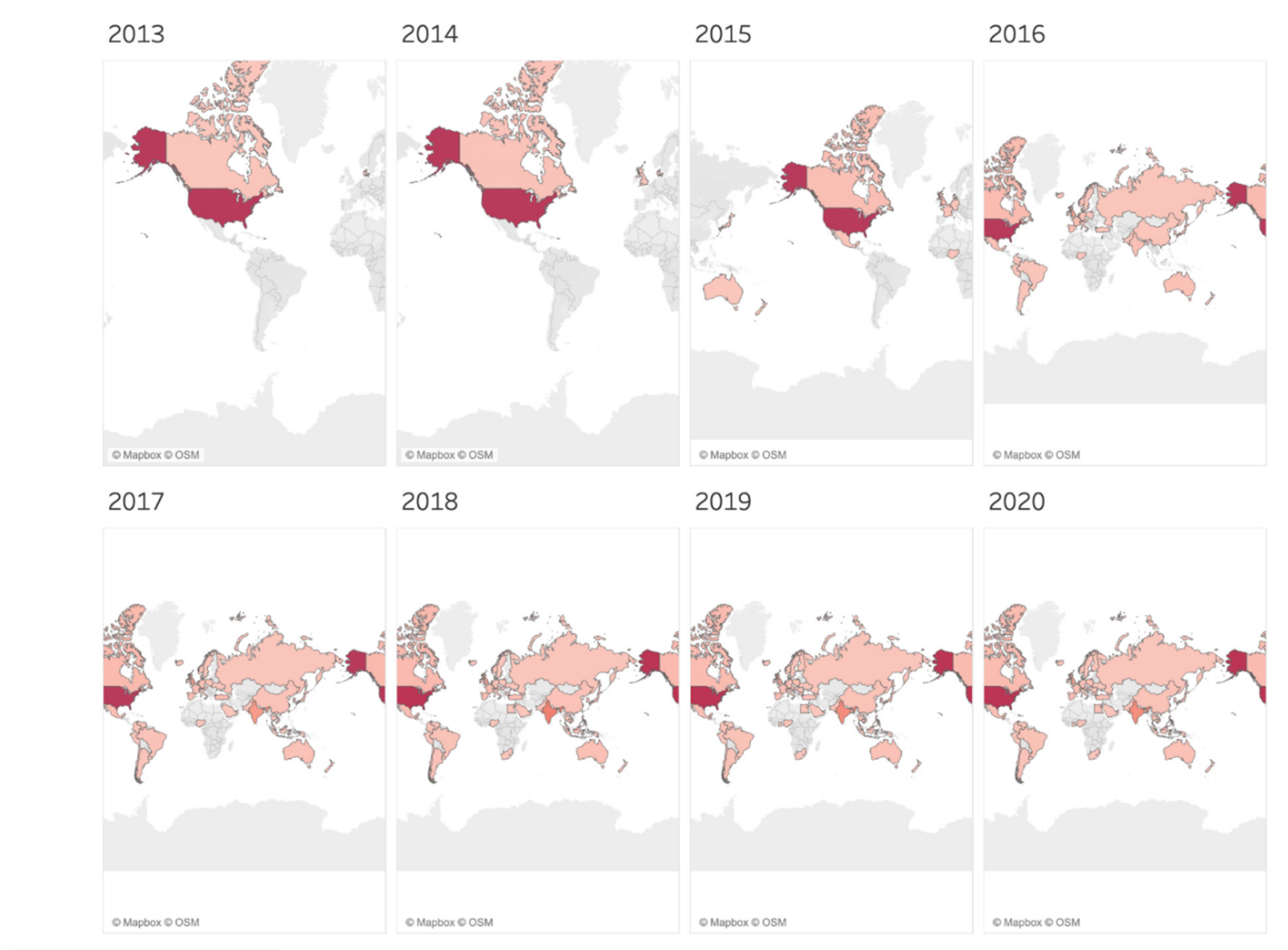

\begin{tabular}{|l|} 
Number of movies and TV shows \\
\hline 1 \\
\hline 1
\end{tabular}

Fig 1. Expansion of Netflix's content globally

Data source: https://www.kaggle.com/shivamb/netflix-shows

This chart shows the total number of productions by each country from 2013-2020. As we can see, the darker the color, the larger amount of content a country produces. In 2013, Netflix's content was mostly focused on North America. This is easy to comprehend since Netflix is founded in the United States. As the time passes, the movie industry in the whole world started blooming, and Netflix expanded its production throughout the globe. There is significant expansion from 2015 to 2017, in which Netflix added more content from Europe and Asia-Pacific region.

However, there are still countries with zero content on Netflix as shown in the map, including most of the African countries and a small part of Europe. Netflix should consider investing more in adding content from such countries to enlarge the number of paid subscribers and adding more diversity in its show selections. 
Volume 17 (2022)
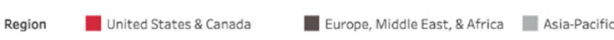

Intatin America
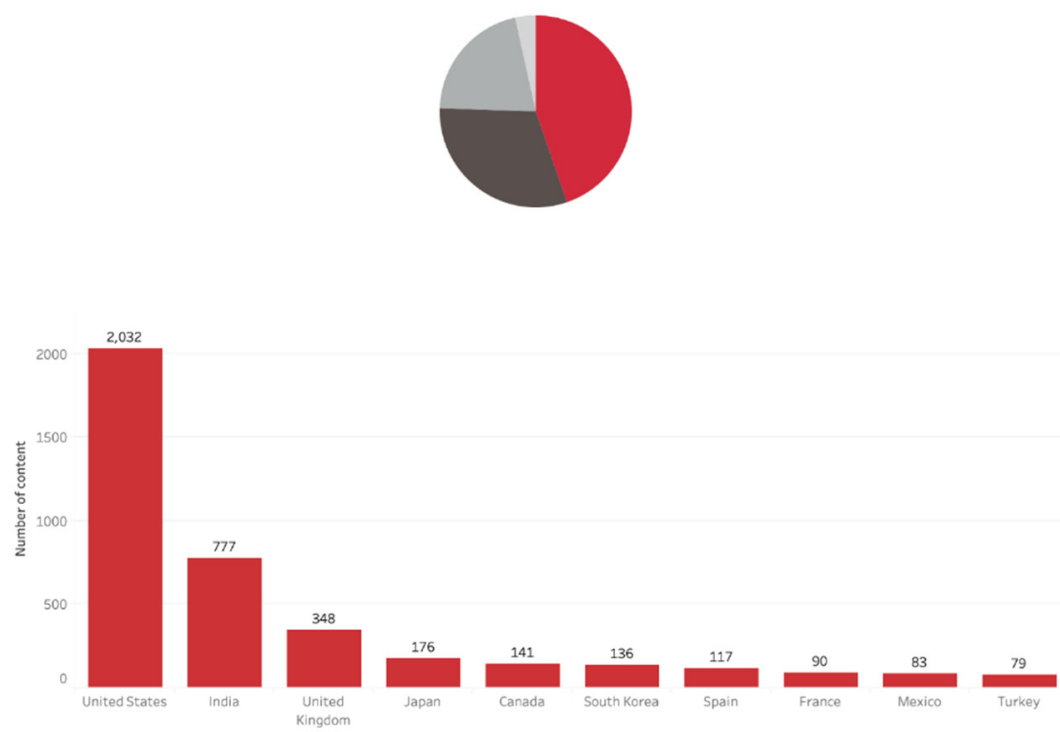

Fig 2. Netflix's content based on regions and contries

Data source: https://www.kaggle.com/shivamb/netflix-shows

The pie chart on the top shows the distribution of different areas' production. The bar chart on the bottom shows the top 10 countries with the largest amount of production.

We can see that U.S. and Canada produced the greatest number of movies and shows for Netflix, followed by Area of Europe, Middle East, \& Africa, Asia-Pacific, and Latin America. To attract more international subscribers, Netflix should import more content from Asia-Pacific and Latin America region.

The United States, India, and the United Kingdom is leading in the number of productions, but fewer productions are seen in Asia-Pacific, Africa, and Middle East. This means Netflix is overdependent on these areas, and their income is not well-balanced from each area. To increase international business and balance their income, Netflix should import more productions from AsiaPacific, Africa, and Middle East.

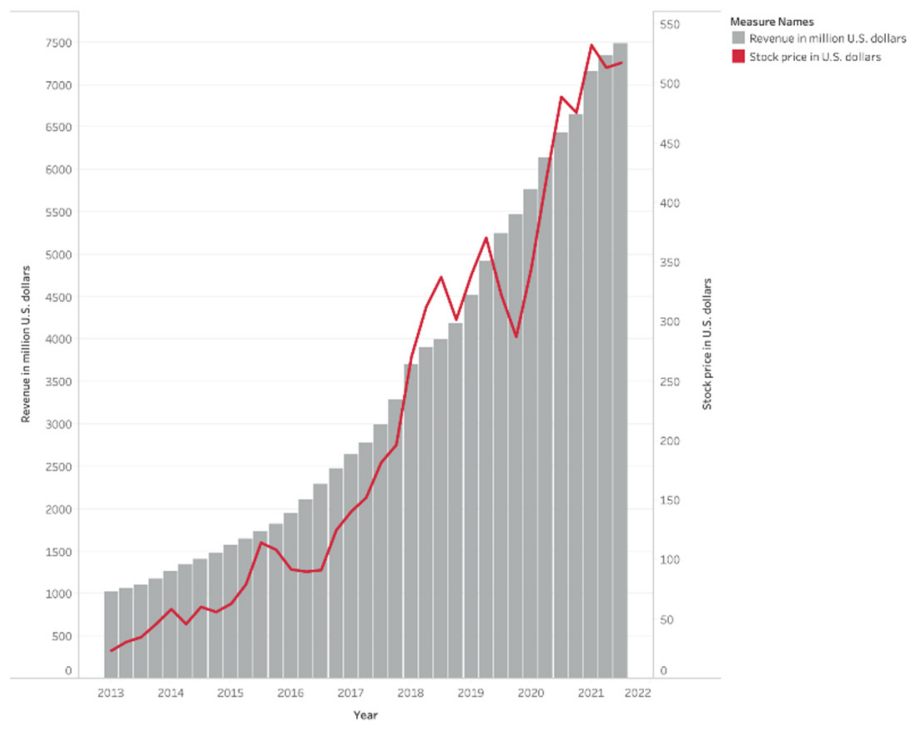

Fig 3. Netflix's financial performance

Data source: https:// finance. yahoo. com/ quote/ NFLX/ history? period1 $=1356998$ 400\& period2

$=1636588800 \&$ interval $=1$ mo\&filter $=$ history \& frequency $=1$ mo\&includeAdjustedClose $=$ true 
This chart shows Netflix's revenue and its stock price from 2013 to 2021 (Q1 and Q2), with the stock price shown as line chart and revenue shown as bar chart. As we can see, the company's revenue is in steady growth throughout the years and is not negatively influenced by the pandemic. Netflix experienced a big drop in its stock price at the beginning of the pandemic but was able to bring it back in mid-2020. The slope shows Netflix experienced the most rapid growth in stock price during this tim. This is due to the globe-wide quarantine and work from home, which forced the audiences to stay home. People are having more free times and eager to watch TV shows and movies. In addition, with the large shut down of movie theatres, many production companies started seeking streaming medias for their screening, which brought huge potential opportunities and for Netflix.

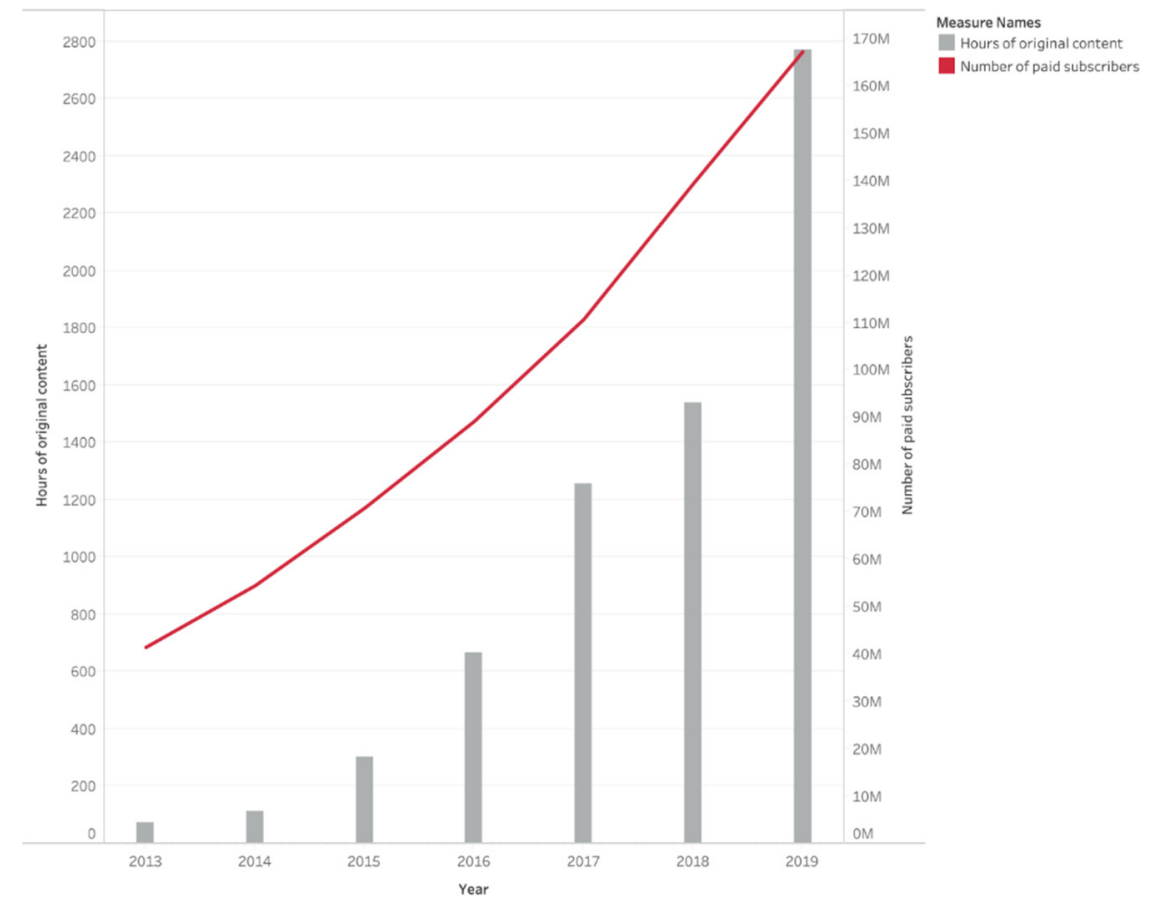

Fig 4. Correlation between Netflix's original content and subscribers Data source: https://backlinko.com/netflix-users\#netflix-statistics

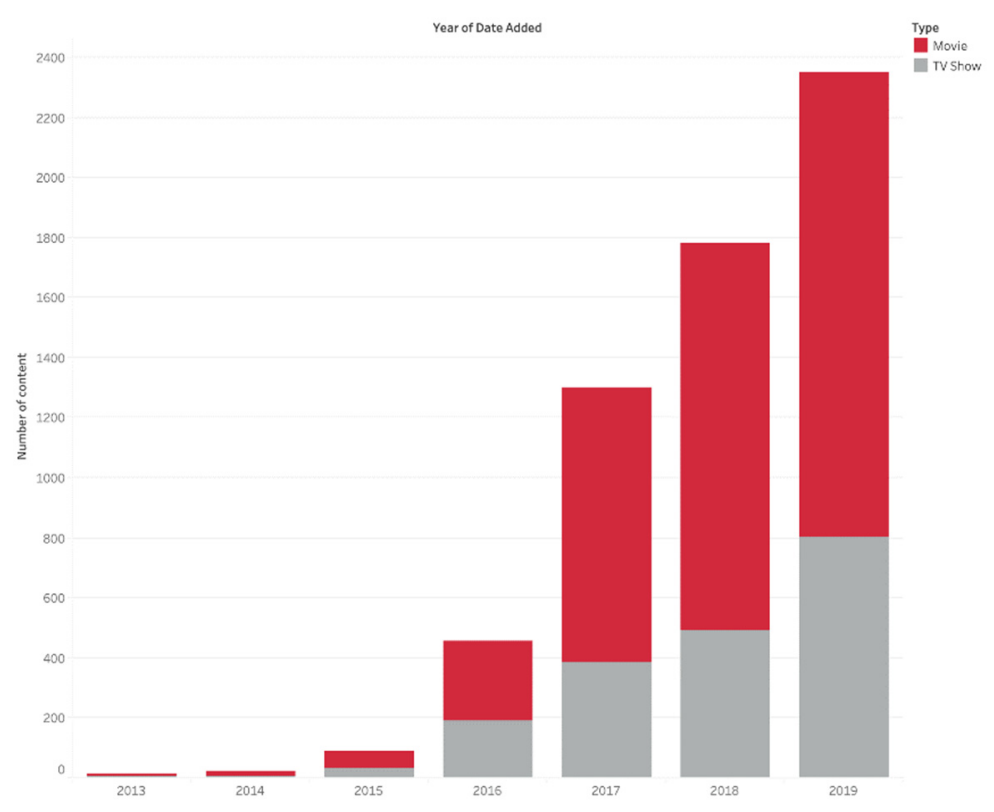

Fig 5. Content addition over the years on Netflix Data source: 
This chart depicts the number of paid subscribers as bar chart, and hours of original content on Netflix as line chart. As we all know, Netflix is famous for its novel and interesting original productions. During merely 6 years between 2013 and 2019, Netflix increased its original content by 37 times. With this growth, Netflix were able to boost its subscribers from 40 million in 2013 to almost 170 million in 2019. It is clear that subscribers enjoyed the original content created by Netflix and putting more attention on providing such content will help Netflix increase its subscriber and revenue. However, as Netflix had the most significant growth in original content during 2018-2019, the speed of growth in subscribers started to slow down. This is hinting that Netflix should also be careful about the quality of its new content because quality is always more important than quantity.

This bar chart shows the number of movies and TV shows added on Netflix from 2013 to 2019. There is significant growth in the total number from 2017 to 2019, in which the streaming media industry around the globe showed prosperity and strength.

Netflix has more movies than TV shows on its platform, and the speed of adding TV shows is clearly slower than that of movies. To attract more subscribers, the company should try to add more TV shows to its platform.

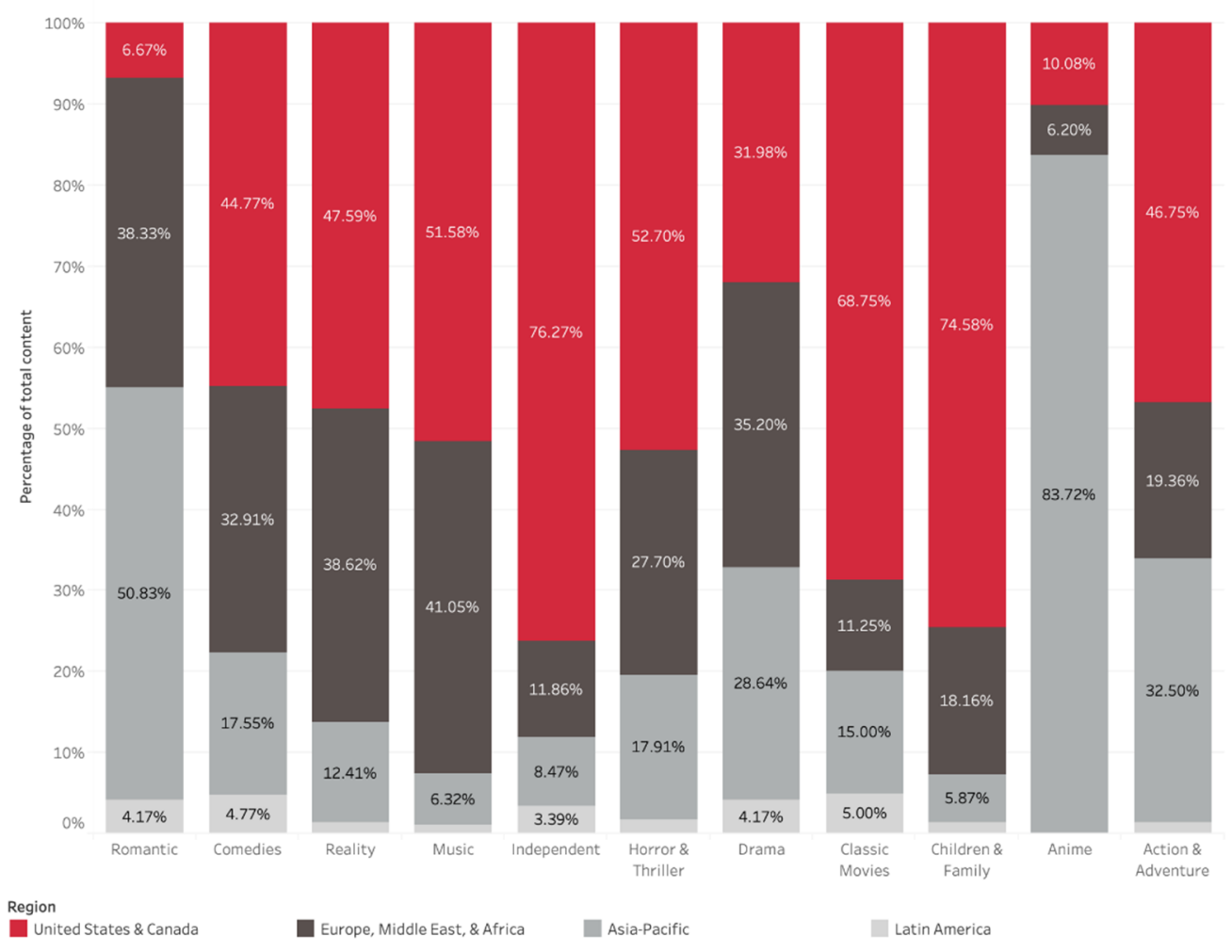

Fig 6. Genre distribution of Netflix shows in different regions (Data source: https://www.kaggle.com/shivamb/netflix-shows)

This stacked bar chart presents the distribution of genres of production in different regions.

It is important to note that each area has its own preference in the making of the creation. For example, North America and Latin America favor Comedies more, while the rest of the world favor Dramas more. Asia-Pacific is probably the only area that have a focus on Anime; North America is probably the most interested in producing children and family themed shows. Knowing this information will help Netflix improve its customization for different subscribers around the globe and produce contents that most fit in with the region's interest. 


\section{Conclusion and Inspiration}

By using techniques of data visualization, this paper analyzed the general trend of development of Netflix, including its global expansion, financial status, relationship between original content and subscribers, content addition, and genre distribution in different regions. Through these charts, it is confident to say that Netflix is on a promising track to future, and is not influenced severely by the Covid-19 pandemic. However, it needs to be careful in the quality of its original content and the diversity of its selection since the audiences will be more and more diverse as the company grows. Moreover, knowing the preference of each region's subscribers will help improve the recommendation system and provide better customization for the audiences. Netflix should continue analyzing their habit and preference to make them stay with the platform and to enlarge the amount of its subscribers.

\section{References}

[1] Bridge, J. A., Greenhouse, J. B., Ruch, D., Stevens, J., Ackerman, J., Sheftall, A. H., Campo, J. V. (2021). Association Between the Release of Netflix's 13 Reasons Why and Suicide Rates in the United States: An Interrupted Time Series Analysis. Elsevier Ltd.

[2] Jasmina Baraković Husić, S. B. (2021). Multidimensional modelling of quality of experience for video streaming. Sarajevo: Elsevier Ltd.

[3] Jo ao Marcos Soares da Silva, R. C. (2021). Is Netflix a threat to the cable TV industry? Evidence from Brazil. Brazil: Elsevier Ltd.

[4] Minjung Shon, D. L. (2021). Are global over-the-top platforms the destroyers of ecosystems or the catalysts of innovation? Seoul: Elsevier Ltd.

[5] Pirongrong Ramasoota, A. K. (2021). "The Netflix effect" in Thailand: Industry and regulatory implications. Bangkok: Elsevier Ltd. 